\title{
Novel synthesis methods for new materials in solid state chemistry
}

\author{
J ETOURNEAU \\ Institut de Chimie de la Matière Condensée de Bordeaux (ICMCB), CNRS, Université Bordeaux 1, 87 Avenue \\ Dr A Schweitzer, 33608 Pessac Cedex, France
}

\begin{abstract}
The most common method used for synthesizing inorganic solids is the so-called 'ceramic method' which involves synthesizing at elevated temperatures and leads to thermodynamically stable phases. This method has a serious limitation because many inorganic solids of current interest are rather metastable and consequently their preparation requires low temperature methods. In this article, we have reported some methods of synthesis which also include methods that belong to soft-chemistry routes. The selected examples presented in this paper are: (i) the intercalation and or deintercalation of oxygen in oxides by electrochemical oxidation or reduction in aqueous or nonaqueous solutions, (ii) the use of chemical agents such as $\mathrm{NO}_{2}$ or borohydrides for obtaining oxides with tunneled and lamellar structures, (iii) a multistage synthesis processing for intercalating, in layered oxygenated materials, anionic species and acrylic monomers and polymers, (iv) the supercritical fluid processing for preparing nitrides, carbon-nitrides, lamellar oxides and oxy-(hydroxy-) fluorides, and (v) the mechanical alloying for synthesizing new Mg-based binary intermetallics.
\end{abstract}

Keywords. Borohydrides; electrochemical oxidation/reduction; intercalation/deintercalation; mechanical alloying; nanoparticles; nitrogen dioxide; soft chemistry; supercritical fluids processing.

\section{Introduction}

Although efforts have been made by the Solid State Chemists in synthesizing novel materials, predicting the composition, the structure, and the properties of new materials pose a challenge. Thus, for the prediction of chemical composition as well as the structure of new materials, and finding the appropriate method of synthesis for obtaining the desired solid, it is necessary to distinguish between 'extended solids' and 'molecular solids'. 'Extended solids', which connect an atom with the next in a continuous network, involve any element of the periodic table and the resulting bond-types vary mostly from ionic to completely covalent. This general observation makes the prediction of their composition difficult, except if we consider that a 'new' compound may be a 'derivative' compound obtained by substitution of chemically similar elements. In contrast, with 'molecular solids' a rational synthesis seems to be easier since it is based mainly on the nature of the covalent bonds between carbon and itself and with a few other elements such as hydrogen, oxygen, nitrogen etc. Furthermore, the formation of nonstoichiometric compounds is never observed in molecular materials in contrast to "extended solids'.

Using the tools of the Solid State Chemists, if we are able to design a new compound that takes into account crystal chemistry reasonings (bond lengths, coordination numbers, structural defects, etc...), quantum chemistry, simulation techniques (lattice energy minimizations, molecular dynamics, Monte Carlo techniques, etc...) (Richard et al 1994), band structure calculations, etc. . ; then the second important step would be choice of the method of synthesis for making the predicted compound. Since we generally ignore the mechanisms by which the reactant atoms rearrange to form the solid with a new structure, the second step poses greater difficulty, whatever the nature of the reactions, for example solid-solid or solid-gas, the problem is to know the mechanism which is involved at the interface of the reactants, in other words it is necessary to take into account the dynarnic aspect of the reaction (Schollhorn 1996). The knowledge of the intermediate stage, between the initial state consisting of the reactants and the final state consisting of the new product, is necessary for monitoring the reaction as well as for choosing the starting materials. An observation in situ of the progress of the reaction is required for the rational synthesis of inorganic solids. This would enable us to understand as to why sometimes a new compound is not formed in a particular synthesis experiment. Thus the problem which is raised may either be thermodynamic, in so far as the formation of the compound does not produce the lowest energy state of the system, or may be kinetic. All these general comments have been already underlined in detail in feature articles by Disalvo (1990) and Gopalakrishnan (1995, 1996).

Since twenty years, many review articles have been devoted to the chemical synthesis of inorganic solid materials (Hagenmuller 1972; Rao and Gopalakrishnan 1986; Corbett et al 1987; Disalvo 1990; Etourneau 1991; 
Rao 1993; Gopalakrishnan 1995, 1996). In the present paper we want to highlight original and significant work being carried out recently in our Institute. We would like to draw your attention to the use of methods of synthesis of materials involving low temperatures either because they are new or because some of these which are already known have recently led to preparation of new interesting materials. The selected examples are: (i) the intercalation and or deintercalation of oxygen in oxides by electrochemical oxidation or reduction in aqueous or nonaqueous solutions, (ii) the use of chemical agents such as $\mathrm{NO}_{2}$ or borohydrides for obtaining oxides with tunneled and lamellar structures, (iii) a multistage synthesis processing for intercalating, in layered oxygenated materials, anionic species and acrylic monomers and polymers, (iv) the supercritical fluid processing for preparing nitrides, carbon-nitrides, lamellar oxides and oxy-(hydroxy-) fluorides, and (v) the mechanical alloying for synthesizing new Mg-based binary intermetallics.

\section{Intercalation and/or deintercalation processes applied to oxides and hydroxides}

The development of 'chimie douce' preparative methods has broadened the field of solid state chemistry to embrace a wide variety of materials either in their metastable forms or with particular textures, which could never have been obtained by any other method (Rouxel et al 1994). This is because of the nature of the reactions product is controlled by kinetics rather than by thermodynamics. These methods can be classified as: (i) those which use the electrochemical potential as the driving force, and (ii) those which are based on chemical redox reactions.

\subsection{The electrochemical synthesis}

In 1990 we discovered that using the electrochemical potential as a 'driving force', it was possible to intercalate oxygen into oxide networks, at room temperature, and correspondingly to overoxidize oxides up to unexpected oxygen stoichiometries (Wattiaux et al 1990; Grenier et al 1998). Basically this reaction can be achieved, thanks to the high oxygen activity resulting from an applied overpotential $\eta$ on an oxide ceramic electrode, according to the reaction:

$$
\begin{gathered}
4 \mathrm{OH}^{-} \rightarrow \mathrm{O}_{2 \mathrm{~g}}^{*}+2 \mathrm{H}_{2} \mathrm{O}+4 e^{-},\left(E_{\mathrm{th}}^{\mathrm{o}}=0.303 \mathrm{~V} \cdot \mathrm{Hg} / \mathrm{HgO},\right. \\
\text { at } \mathrm{pH}=14) .
\end{gathered}
$$

Using the Nernst relation, this oxygen activity can be considered to be equivalent, at room temperature, for a few hundred $\mathrm{mV}$ of overpotential, to a very high oxygen pressure. Indeed such an activity can induce the formation of oxide films on metal electrodes. This has been recently used for growing tailored thick films of oxides as $\mathrm{Al}_{2} \mathrm{O}_{3}$, $\mathrm{ZnO}, \mathrm{CuO}, \ldots$, but they are usually passivating. However, replacing a metallic electrode by an oxide, and provided that a diffusion path exists within the oxide matrix, oxygen atoms have been evidenced to migrate easily.

Thus, experiments were carried out in an alkaline solution, in air, at room temperature; the material to be oxidized can either be a dense ceramic, a thin film or even a crystal. The most striking result obtained was in 1990 for $\mathrm{La}_{2} \mathrm{CuO}_{4}$. This insulating antiferromagnetic compound was transformed within a few hours into a metallic and superconducting oxide with $T_{\mathrm{c}}=44 \mathrm{~K}$, the highest transition temperature ever obtained for this phase. Then, various compounds represented by $A_{x} M_{z} O_{y}$, whose structures derive from perovskite, were oxidized. These essentially belong to the so-called $\mathrm{A}_{n} \mathrm{M}_{n} \mathrm{O}_{3 n-1}$ and $\mathrm{A}_{n+1} \mathrm{M}_{n} \mathrm{O}_{3 n+1}$ series with $\mathrm{A}=\mathrm{La}, \mathrm{Nd}, \mathrm{Sr}$ or $\mathrm{Ba}$, and $\mathrm{M}=\mathrm{Fe}, \mathrm{Co}, \mathrm{Ni}$, and $\mathrm{Cu}$.

2.1 a Experimental procedure: The electrochemical system comprises of a power supply (a potentiostat), and an electrolyte cell of three-electrode type that uses alkaline solution, $1 \mathrm{M} \mathrm{NaOH}$ or $\mathrm{KOH}$, as the electrolyte. The electrolyte concentration of $1 \mathrm{M}(\mathrm{pH}=14)$ is considered as the optimal one. Figure 1 shows a scheme of the electrochemical cell, the major components of which are the three electrodes: (i) the working electrode, (ii) the reference electrode and (iii) the counter electrode.

(i) The working electrodes are usually ceramic pellets of the materials to be oxidized; their relative densities are around $80 \%$, which seems to be the optimal density allowing a good permeation of the electrolyte into ceramic. A rotating working electrode is preferred to a fixed one as it produces better convection between the electrolyte in the ceramic electrode and in the bulk

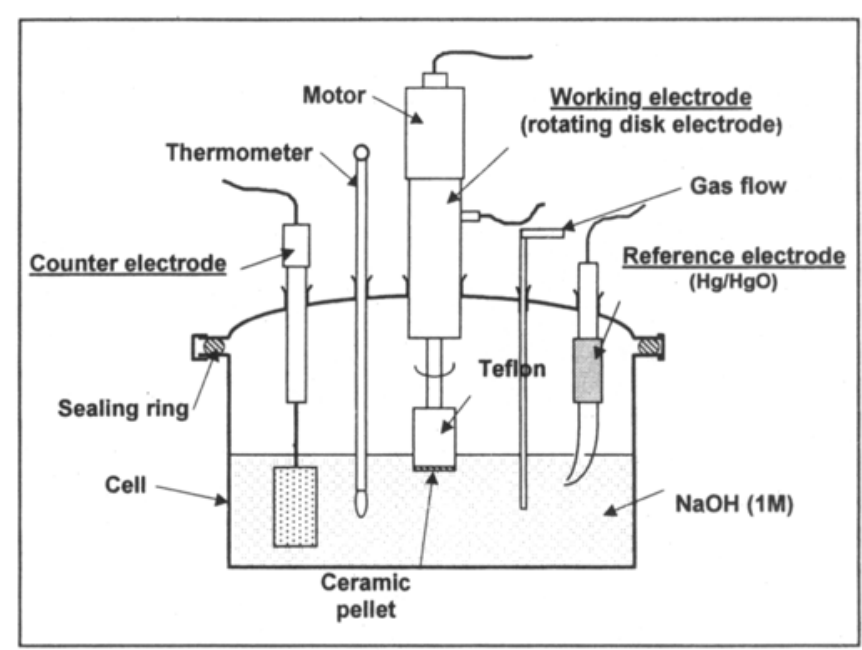

Figure 1. The electrochemical cell with three electrodes for experiments at $25^{\circ} \mathrm{C}-90^{\circ} \mathrm{C}$. 
solution. It also prevents evolved gas bubbles $\left(\mathrm{O}_{2}\right)$, if any, from accumulating on the electrode surface. A stable and ohmic contact between the ceramic pellet and the metallic support (made of brass), which is connected with external circuit, is required for the electrochemical process and meaningful data measurements. The assembly is achieved thanks to a gold foil and silver paste, the whole being embedded in a resin.

(ii) The reference electrode is a mercury-mercury oxide electrode $(\mathrm{Hg} / \mathrm{HgO})$ that has excellent stability in alkaline solutions. Its standard potential (at $a_{\mathrm{OH}^{-}}=1$ and $T=298 \mathrm{~K}$ ) is $0.098 \mathrm{~V}$ relative to SHE. All the potentials quoted in this work are referred to this electrode.

(iii) The counter electrode is designed to have a large surface area. The materials used are usually good electronic conductors, such as foil of gold or platinum or piece of glassy carbon.

2.1b Electrochemical aspects: Various compounds represented by $\mathrm{A}_{x} \mathrm{M}_{z} \mathrm{O}_{y}$, whose structures derive from perovskite, have been oxidized. These essentially belong to the so-called $\mathrm{A}_{n} \mathrm{M}_{n} \mathrm{O}_{3 n-1}$ and $\mathrm{A}_{n+1} \mathrm{M}_{n} \mathrm{O}_{3 n+1}$ series with $\mathrm{A}=\mathrm{La}, \mathrm{Nd}, \mathrm{Sr}$ or $\mathrm{Ba}$; and $\mathrm{M}=\mathrm{Fe}, \mathrm{Co}, \mathrm{Ni}$, and $\mathrm{Cu}$. The oxidation reaction can be summarized as follows:

$$
\mathrm{A}_{x} \mathrm{M}_{y} \mathrm{O}_{z}+2 \delta \mathrm{OH} \rightarrow \mathrm{A}_{x} \mathrm{M}_{y} \mathrm{O}_{z+\delta}+\delta \mathrm{H}_{2} \mathrm{O}+2 \delta e^{-},
$$

where $\delta$ represents the amount of inserted oxygen. The fact that the oxygen atoms and not hydroxide, $\mathrm{OH}^{-}$, species are intercalated, was earlier demonstrated by several groups using various techniques such as TGA and chemical analysis, coulometric titration, ' $\mathrm{H} N \mathrm{NR}$, IR, and Mössbauer spectroscopies (see examples below).

Figure 2 shows a typical $I-E$ voltammetry curve (anodic part) measured on a rotating electrode. This example is concerned with the brownmillerite-type, $\mathrm{Sr}_{2} \mathrm{Co}_{2} \mathrm{O}_{5}$,

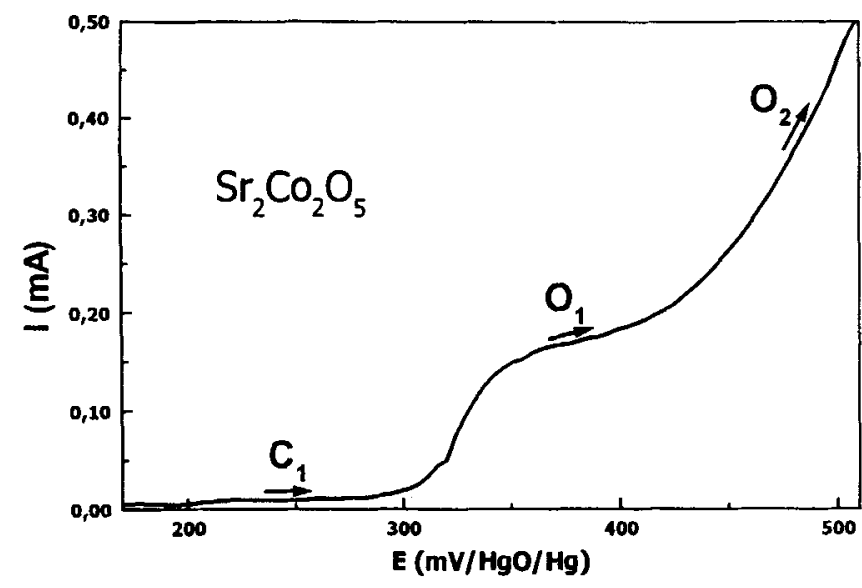

Figure 2. Voltammetry curve (anodic part) of a brownmillerite $\mathrm{Sr}_{2} \mathrm{Co}_{5} \mathrm{O}_{5}$-type electrode in a $1 \mathrm{M} \mathrm{NaOH}$ solution (RDE $2000 \mathrm{rpm}, \mathrm{d} E / \mathrm{d} t=150 \mathrm{mV} / \mathrm{min}, T=300 \mathrm{~K}$, under air). Note the oxidation plateau $O_{1}$ observed before oxygen evolution. materials. Three regions can be seen in this curve: (i) A linear part immediately after the polarization begins $\left(\mathrm{C}_{1}, E<300 \mathrm{mV}\right)$, and is assigned to charging of the double layer on the interface between the electrolyte and the electrode surface. (ii) A wave shape part $\left(\mathrm{O}_{1}, E=300\right.$ $450 \mathrm{mV}$ ) with the half-wave potential, is ascribed to the oxidation of the electrode material according to reaction (2) wherein it corresponds formally to the transformation of $\mathrm{Co}^{3+}$ to $\mathrm{Co}^{4+}$. (iii) At higher potentials the current intensity once again increases with the evolution of gaseous oxygen in the third region $\left(\mathrm{O}_{2}, E>450 \mathrm{mV}\right)$, according to reaction (1).

Then two kinds of experiments can be carried out: (i) potentiostatic oxidation experiments that use a steady potential set in the oxidation plateau, depending on the starting material (e.g. $400 \mathrm{mV}$ for $\mathrm{Sr}_{2} \mathrm{Co}_{2} \mathrm{O}_{5}$ ). The oxidation reaction is followed by measuring the time dependence of the potential at rest-the open circuit voltage, $E_{\mathrm{OCV}}$, measured after $15 \mathrm{~min}$, increases with the polarization time. Actually it can be directly correlated to the chemical composition, i.e. to the amount of $\mathrm{Co}^{2+} / \mathrm{Co}^{3+} / \mathrm{Co}^{4+}$ or to oxygen stoichiometry $(3-y)$ and (ii) galvanostatic experiments that are more convenient for controlling the reaction kinetics, have been used by several groups. As for the lithium intercalation into dichalcogenides or oxides, using small current intensities (a few $\mu \mathrm{A}$ ), several potential steps are observed. Thus in the $\mathrm{La}_{2} \mathrm{CuO}_{4+\delta}$ system $(\delta \approx 0.04$ and 0.09$)$ such a feature characterizes the existence of two phases. The two phases exhibit superconducting transitions at 32 and $44 \mathrm{~K}$, respectively. Similarly, in the $\mathrm{SrCoO}_{3-y}$ system, several steps are observed involving once again the formation of various intermediate phases before the last stage of oxidation is reached that leads to fully oxidized material, $\mathrm{SrCoO}_{3}$. Similar features have also been reported for $\mathrm{La}_{2} \mathrm{NiO}_{4+\delta}$ and $\mathrm{Nd}_{2} \mathrm{NiO}_{4+\delta}$, which confirm the close analogy with cationic intercalation phenomena.

Thus while considering the electrochemical aspects, two remarks need to be emphasized: (i) the alkali solution used in the process can be corrosive with regard to oxides to be oxidized, for example for the oxide, $\mathrm{YBa}_{2} \mathrm{Cu}_{3} \mathrm{O}_{7-\delta}$. This drawback could be avoided by using a nonaqueous and aprotic solution which consists of a mixture of $\mathrm{DMSO} / \mathrm{NaClO}_{4} / \mathrm{KO}_{2}$. We have shown, very recently, that this new electrolyte gives promising results for obtaining the superoxygenated $\mathrm{La}_{2} \mathrm{CuO}_{4+\delta}$ (Jacob et al 1998) and (ii) the electrochemical process could also be used for deintercalating the oxygen atoms, showing thereby that the electrochemical oxidation is a reversible process. Thus, we have obtained $\mathrm{La}_{2} \mathrm{CuO}_{4}$ and $\mathrm{La}_{2} \mathrm{NiO}_{4}$ from the superoxygenated oxides $\mathrm{La}_{2} \mathrm{CuO}_{4+\delta}$ and $\mathrm{La}_{2} \mathrm{NiO}_{4+\delta}$, respectively (Grenier et al 1998).

2.1c Structural aspects: Two main features must be examined for intercalation of anionic or cationic species 
in a compound: (i) the crystal structure, which must offer free spaces as for example channels or interlayer spaces and (ii) the electrostatic potential along the diffusion paths, which, according to its sign and value, can either favour or disfavour the intercalation of the anionic or cationic species.

The main crystal structural types that have been studied, are represented in figure 3. All these types are related to the perovskite structure. The crystal structure types that belong to the $\mathrm{A}_{n} \mathrm{M}_{n} \mathrm{O}_{3 n-1}$ series are compounds that can be considered as oxygen-deficient perovskites,

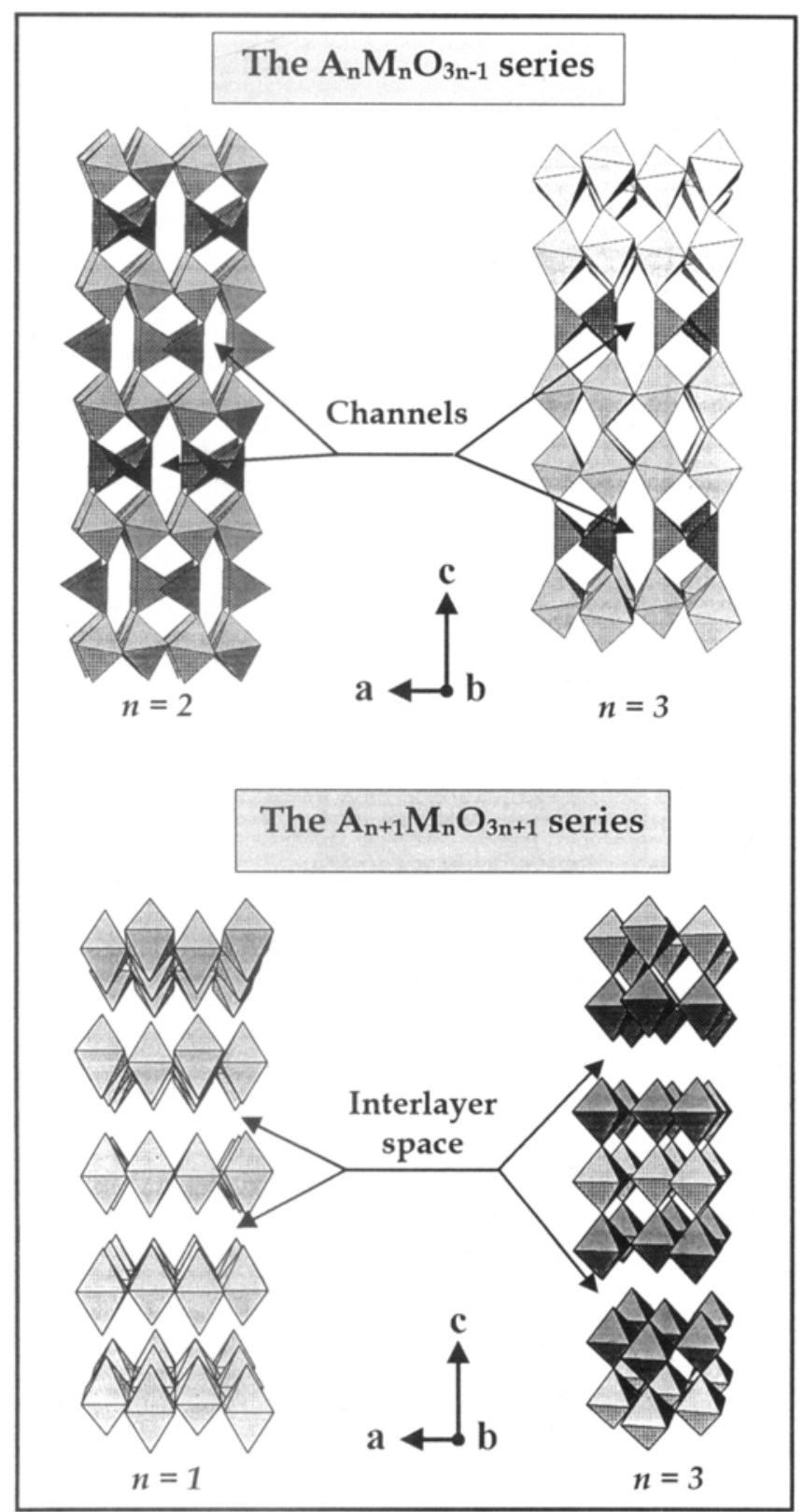

Figure 3. Representation of the main crystal structural types of the $\mathrm{A}_{n} \mathrm{M}_{n} \mathrm{O}_{3 n-1}$ and $\mathrm{A}_{n+1} \mathrm{M}_{n} \mathrm{O}_{3 n+1}$ series showing the channels and interlayers space allowing the oxygen intercalation.
$\mathrm{AMO}_{3-y}(n \geq 2 ; 0 \leq y \leq 0 \cdot 5)$. Their structures exhibit channels perpendicular to the $z$ axis, which can constitute diffusion paths for intercalating oxygen atoms. However, this precondition in itself is not sufficient as some compounds, especially those containing calcium, do not intercalate oxygen. A tentative and simple model can be proposed by calculating the electrostatic potentials along the channels. This was proposed for $\mathrm{Ca}_{2} \mathrm{Fe}_{2} \mathrm{O}_{5}, \mathrm{Sr}_{2} \mathrm{Fe}_{2} \mathrm{O}_{5}$, and $\mathrm{Sr}_{2} \mathrm{LaFe}_{3} \mathrm{O}_{8}$. While the electrostatic potentials along the diffusion paths are negative for $\mathrm{Ca}_{2} \mathrm{Fe}_{2} \mathrm{O}_{5}$, they are positive for $\mathrm{Sr}_{2} \mathrm{Fe}_{2} \mathrm{O}_{5}$, and $\mathrm{Sr}_{2} \mathrm{LaFe}_{3} \mathrm{O}_{8}$. Therefore, for a negatively-charged oxygen species, its diffusion along the channels in $\mathrm{Sr}_{2} \mathrm{Fe}_{2} \mathrm{O}_{5}$, and $\mathrm{Sr}_{2} \mathrm{LaFe}_{3} \mathrm{O}_{8}$ compounds may be favoured by the Coulomb energy, but it is not so for $\mathrm{Ca}_{2} \mathrm{Fe}_{2} \mathrm{O}_{5}$. Electrochemical experiments confirm that actually it is not possible to insert oxygen within the networks of $\mathrm{Ca}_{2} \mathrm{Fe}_{2} \mathrm{O}_{5}$, and $\mathrm{Ca}_{2} \mathrm{LaFe}_{3} \mathrm{O}_{8}$.

The crystal structure types that belong to the Ruddlesden-Popper, $\mathrm{A}_{n+1} \mathrm{M}_{n} \mathrm{O}_{3 n+1}$ series, show that though in these compounds such channels do not appear so clearly, their structure could be considered as lamellar (figure 3 ), the additional oxygen atoms being inserted between the $\mathrm{A}_{2} \mathrm{O}_{2}$ layers.

From a structural viewpoint, $\mathrm{X}$-ray diffraction analysis shows the materials to remain well crystallized after the electrochemical treatment. This demonstrates the oxygen intercalation to be a topotactic reaction, and easy diffusion paths exist within these structures. Indeed, common features can be found in both series of materials, considering that all these. structures are based on a stacking of compact hexagonal $\mathrm{A}_{x} \mathrm{O}_{y}$ layers between which metal cations $M$ are located (Darriet and Subramanian 1995; Dussarat et al 1995). It can easily be noticed that in the ideal $\mathrm{K}_{2} \mathrm{NiF}_{4}$-type structure, characterized by a stacking of $\left(\mathrm{A}_{2} \mathrm{O}_{4} \square_{2}\right)$ layers, oxygen rows along the [110] direction are missing (figure 4). The stacking of $\mathrm{A}_{x} \mathrm{O}_{y}$ layers finally gives rise to channels in the $A_{n} \mathrm{M}_{n} \mathrm{O}_{3 n-1}$ series, and rather interlayers space in the $\mathrm{A}_{n+1} \mathrm{M}_{n} \mathrm{O}_{3 n+1}$ series.

\subsection{Intercalation and/or deintercalation processes using chemical agents and involving redox reactions}

Previous examples were concerned with electrochemically monitored reactions in aqueous solutions. Oxidative deintercalation processes can also be achieved using chemical agents: the most well-known example being the lithium deintercalation from some oxide (e.g. $\mathrm{LiCoO}_{2}$ or $\mathrm{LiNbO}_{2}$ ) or sulfide (e.g. $\mathrm{LiTiS}_{2}$ ) networks using strong oxidizing agents such as $\mathrm{I}_{2}, \mathrm{Br}_{2}, \mathrm{MoF}_{6} \ldots$ in acetonitrile (Wizanski et al 1989; Amatucci et al 1996; Gupta and Manthiram 1996). Oxidizing intercalation processes in aqueous solutions containing species such as $\mathrm{MnO}_{4}^{-}, \mathrm{BrO}^{-}$ or $\mathrm{ClO}^{-}$which were used, for instance, for overoxidizing cuprates as $\mathrm{La}_{2} \mathrm{CuO}_{4+\delta}$ or $\mathrm{LaCuO}_{2+\delta}$ can also 
be mentioned here (Takayama-Muromachi et al 1993; Trari et al 1994).

2.2a Oxidation by $\mathrm{NO}_{2}$ gas: We have recently investigated an alternative reaction which involves oxidation by gaseous $\mathrm{NO}_{2}$ and particularly its reaction with ammonium ions $\mathrm{NH}_{4}^{+}$at $T \leq 350^{\circ} \mathrm{C}$ (Petit et al 1995). Such a process implies the $\mathrm{N}^{+\mathrm{IV}} / \mathrm{N}^{-111}$ redox couple, as in the explosive decomposition of $\mathrm{NH}_{4} \mathrm{NO}_{3}$. In addition, we may expect the in situ destruction of $\mathrm{NH}_{4}^{+}$in the starting materials according to the following scheme:

$$
\mathrm{NO}_{2(\mathrm{~g})}+\mathrm{NH}_{4}^{+}+e^{-} \rightarrow \mathrm{N}_{2}^{*}+2 \mathrm{H}_{2} \mathrm{O}^{-} \text {. }
$$

This mole-to-mole reaction yields two neutral species: gaseous $\mathrm{H}_{2} \mathrm{O}$ and $\mathrm{N}_{2}$ as by-products. These can be easily expelled out of the material with respect to their size which is close to that of $\mathrm{NH}_{4}^{+}$cations. Therefore one can presume a topotactic destruction of these big cations, leaving thereby large empty sites in the final compound. A point to note is that this redox reaction requires one electron.

Typically, powdered samples of the starting material are treated at temperatures ranging from $20^{\circ} \mathrm{C}$ to $350^{\circ} \mathrm{C}$ with a mixture of $\mathrm{NO}_{2} / \mathrm{N}_{2}$ (figure 5). Depending on the starting materials, the reaction can be violent. Various types of reactions occur which can be classified as:

Topotactic reactions-Here the initial structure remains unchanged after the in situ destruction of $\mathrm{NH}_{4}^{+}$. The first

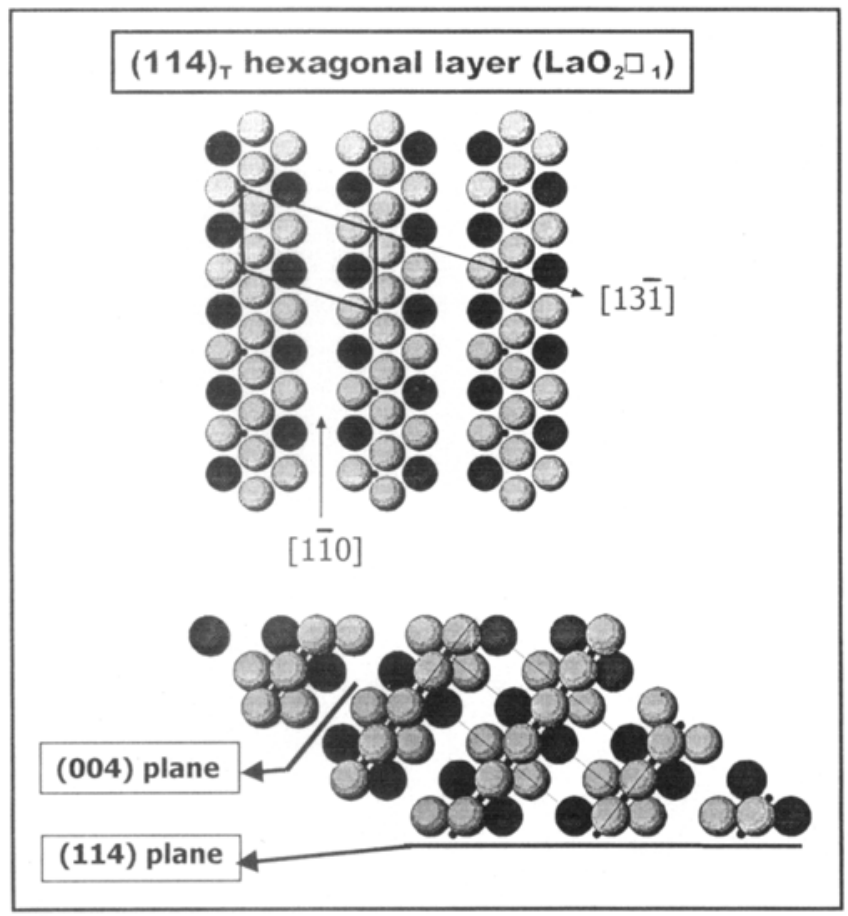

Figure 4. Representation of the $\mathrm{La}_{2} \mathrm{O}_{2}$ compact hexagonal type layers showing the missing rows of oxygen constituting the diffusion paths in the ideal $\mathrm{La}_{2} \mathrm{CuO}_{4}$ structure. example of this reaction deals with the hexagonal tungsten bronzes, $\left(\mathrm{NH}_{4}\right)_{x} \mathrm{WO}_{3}$. These materials are prepared by the controlled reduction of $\left(\mathrm{NH}_{4}\right)_{10} \mathrm{~W}_{12} \mathrm{O}_{41}, 5 \mathrm{H}_{2} \mathrm{O}$ under $\mathrm{Ar} / \mathrm{H}_{2}(5 \%)$ at c.a. $370^{\circ} \mathrm{C}$. A treatment of this dark blue sample by $\mathrm{NO}_{2}$, for $3 \mathrm{~h}$, at temperatures around 250 $300^{\circ} \mathrm{C}$ leads to a well-crystallized white powder, this colour being characteristic of the oxidation of the cations from $\mathrm{W}^{5+}$ to $\mathrm{W}^{6+}$. The absence of ammonium ions from this powder was checked by the Kjeldahl method, and various physical characterizations reveal that the final compound is an hexagonal form of $\mathrm{WO}_{3}$. This was confirmed by the $\mathrm{X}$-ray diffraction pattern as well as by the electron microscopy image which showed presence of large tunnels that are characteristic of $\mathrm{h}-\mathrm{WO}_{3}$ (figure 6). However, the lattice parameters are somewhat different from those previously reported for $\mathrm{h}-\mathrm{WO}_{3}$ which were obtained by a reconstructive process (doubling of $c$ ) (Gerand et al 1979).

The second example of topotactic reactions deals with the ammonium molybdenum oxide. The starting compound is obtained from $\mathrm{Na}_{2} \mathrm{MoO}_{4}, 2 \mathrm{H}_{2} \mathrm{O}$ by cationic exchange in a solution of $\mathrm{NH}_{4} \mathrm{Cl}$, the resulting material being ammonium and molybdenum deficient with a composition close to $\left(\mathrm{NH}_{4}\right)_{0.7} \mathrm{Mo}_{5.3} \mathrm{O}_{18} \mathrm{H}_{3.4}$, but containing only Mo(+IV). XRD analysis revealed a single phase with a hexagonal symmetry $(a=10.583 \AA, c=3.724 \AA)$. The $\mathrm{NO}_{2}$ treatment $\left(3 \mathrm{~h}, 150^{\circ} \mathrm{C}\right.$ to $\left.300^{\circ} \mathrm{C}\right)$ retains the parent structure as in the first example, and the final material was identified to be pure hexagonal $\mathrm{MoO}_{3}$. One should point out that in this case no oxidation of the cation is required, which raises the question of the provenance of the electron in reaction (3). Two assumptions can be made: (i) either there is an oxidation of oxygen anions according to the following reaction $\left(\mathrm{O}^{2-} \rightarrow 1 / 2 \mathrm{O}_{2}+2 e^{-}\right)$, the reaction (3) remaining the basic one, (ii) or the reaction with

\section{Apparatus for $\mathrm{NO}_{2}$ treatment:}

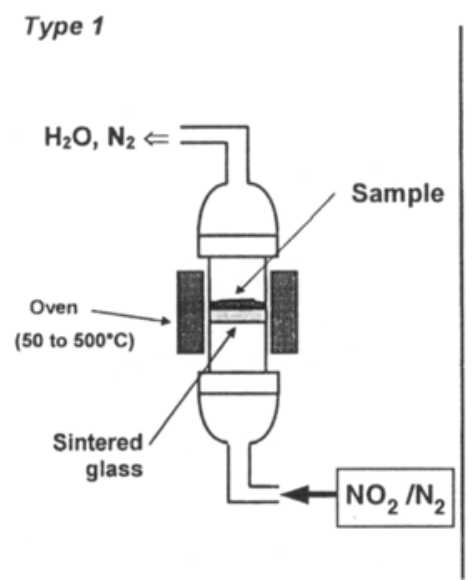

Type 2

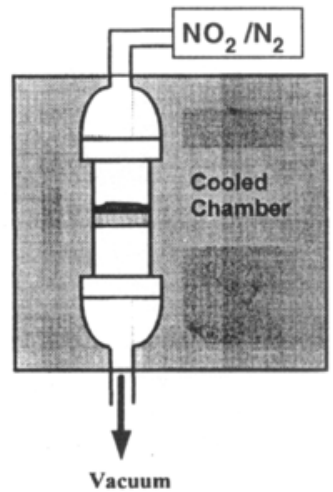

Figure 5. Apparatus for $\mathrm{NO}_{2}$ treatment. 
$\mathrm{NO}_{2}$ occurs via a two-step process, the first one being the destruction of $\mathrm{NH}_{3}$ leading to the formation of an hydrate or hydroxide without oxidation of the material, according to a scheme which only involves an internal redox process:

$$
4 \mathrm{NH}_{4}^{+}+3 \mathrm{NO}_{2(\mathrm{~g})} \rightarrow 4 \mathrm{H}^{+}+7 / 2 \mathrm{~N}_{2}^{\prime}+6 \mathrm{H}_{2} \mathrm{O}^{\prime \prime}
$$

This hydrate or hydroxide can then be thermally decomposed at moderate temperatures.

Non topotactic reactions-In these reactions, as pointed out, the reaction of ammonium compounds may sometimes be violent resulting in destruction of the parent structure, e.g. $\mathrm{NH}_{4} \mathrm{VO}_{3}$ which crystallizes with the structure of $\alpha-\mathrm{NaVO}_{3}$ made up of $\left(\mathrm{VO}_{4}\right)$ chains of tetrahedra. This compound was treated with $\mathrm{NO}_{2}$ at various temperatures. At $100^{\circ} \mathrm{C}$, within a few minutes, it transforms into the well crystallized $\alpha-\mathrm{V}_{2} \mathrm{O}_{5}$, whose lamellar structure is completely different from that of the starting material $\left(\mathrm{V}^{5+}\right.$ cations are located in corner-sharing pyramids).

$2.2 \mathrm{~b}$ The chemical reduction by solutions of borohydrides: Recently borohydride solutions have been reassessed for preparing nanoparticles and low valent oxides at room temperature (Zhang and Manthiram 1996; Tsang et al 1996). According to the thermodynamical data, the redox potential of the following reaction:

$$
\mathrm{H}_{2} \mathrm{BO}_{3}^{-}+5 \mathrm{H}_{2} \mathrm{O}+8 e^{-} \Leftrightarrow \mathrm{BH}_{4}^{-}+8 \mathrm{OH}^{-},
$$

is $E_{0}=-1.24 \mathrm{~V} / \mathrm{SHE}$. Because of this high value of redox potential and in order to prevent water decomposition, sodium or potassium borohydrides should be stabilized in alkaline solution.

An interesting application of these borohydride reducing solutions is in the preparation of crystallized oxides at room temperature, which we have recently developed (Petit et al 1998). Two types of experiments have been carried out: (i) wherein the starting oxide is beforehand dissolved, and (ii) wherein it is not dissolved.

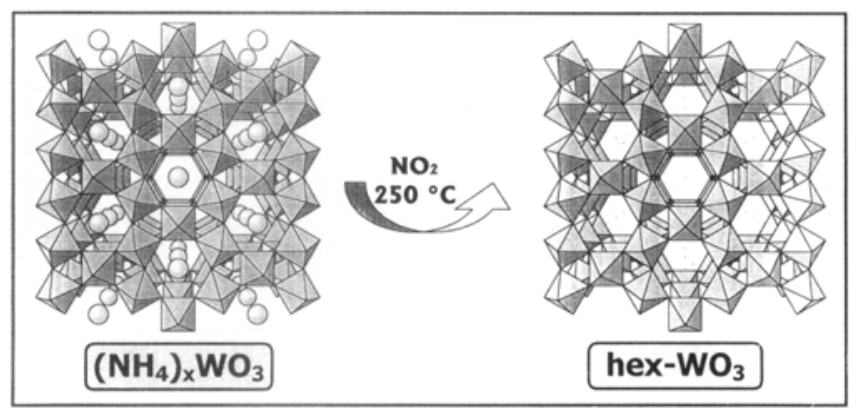

Figure 6. Hexagonal structures of $\left(\mathrm{NH}_{4}\right)_{2} \mathrm{WO}_{3}$ and $\mathrm{WO}_{3}$, showing the large empty channels after $\mathrm{NO}_{2}$ treatment.
For the preparation of $\left(\mathrm{NH}_{4}\right)_{2} \mathrm{~V}_{3} \mathrm{O}_{8}$ by precipitation the starting material $\alpha-\mathrm{V}_{2} \mathrm{O}_{5}$ is dissolved in $1 \mathrm{M} \mathrm{KOH}$ solution. $\mathrm{NH}_{4} \mathrm{Cl}$ is then added in excess, the $\mathrm{pH}$ being close to 10.5 . The reduction of $\mathrm{V}^{5+}$ to $\mathrm{V}^{4+}$ is obtained by addition of the solution of $\mathrm{NaBH}_{4}$ under nitrogen atmosphere. This is followed by slowly lowering the $\mathrm{pH}$ down to 7.5 by adding diluted $\mathrm{HCl}$ when the black ammonium vanadyl vanadate $\left(\mathrm{NH}_{4}\right)_{2} \mathrm{~V}_{3} \mathrm{O}_{8}$ precipitates. After filtration, washing and drying, the material is characterized by chemical analysis and TGA, and its $\mathrm{X}$-ray diffraction pattern shows a rather well-crystallized compound, which has been identified as the 'black hydrate of vanadium' that had been earlier synthesized by reduction, at $100^{\circ} \mathrm{C}$, for $24 \mathrm{~h}$, using $\mathrm{Zn}$ as the reducing agent. Our method on the otherhand, gives a similar result within $1 \mathrm{~h}$.

The structure of this compound is built up of $\mathrm{V}_{3} \mathrm{O}_{8}$ sheets formed from the condensation and reduction of $\left(\mathrm{VO}_{4}\right)^{3-}$ soluble species, between which ammonium ions are inserted as pillars. It is quite different from that of $\alpha-\mathrm{V}_{2} \mathrm{O}_{5}$.

A point to note is that under more or less similar conditions amorphous $\mathrm{Na}_{x} \mathrm{WO}_{3}$, has been prepared, which emphasizes that experimental conditions are of prime importance (Manthiram and Tsang 1996).

The preparation of $\mathrm{K}_{x} \mathrm{WO}_{3}$ involves a topotactic reduction. In the preceding discussion we described the preparation of hexagonal $\mathrm{WO}_{3}$ which contains large tunnels into which various chemical species can be easily inserted. Thus the reduction of $h-W_{3}$ by $\mathrm{KBH}_{4}$ is carried out in a solution in which $\mathrm{h}-\mathrm{WO}_{3}$ is mixed with an excess of $\mathrm{KCl}$. pH is kept close to 7.5. Within a few minutes the white starting material turns blue. The blue powder is then filtered and dried. X-ray diffraction confirms that the hexagonal structure is preserved. Electron microprobe analysis of it reveals that the content of potassium is close to 0.27 , which is in agreement with the value expected from the addition of borohydride $(x \approx 0 \cdot 30)$.

\section{$2.2 \mathrm{c}$ A multistage synthesis processing for intercalating} anionic species in lamellar oxides or preparing new oxyhydroxides: To exemplify the interest in multistage synthesis processing in solid state chemistry, we have chosen the case of the layer double hydroxides (LDHs) which are well known for their anionic exchange properties and for their use as precursors of new catalytic materials (Jones and Chibwe 1990; Cavani et al 1991). Their structure consists of a stacking of brucite type slabs $\left[\mathrm{M}_{1-y}^{\mathrm{II}} \mathrm{L}_{y}^{\mathrm{III}}(\mathrm{OH})_{2}\right]$, made of edge sharing $(\mathrm{M}, \mathrm{L}) \mathrm{O}_{6}$ octahedra, with water molecules and $\mathrm{X}^{n-}$ anions intercalated within the interslab space, represented by the general formula:

$$
\left[\mathrm{M}_{1-y}^{\mathrm{II}} \mathrm{L}_{y}^{\mathrm{III}}(\mathrm{OH})_{2}\right]^{y}+x_{y / n}^{n-}\left(\mathrm{H}_{2} \mathrm{O}\right)_{z}
$$


The anions are inserted in order to compensate for the excess positive charge owing to the partial substitution of trivalent cations (L) for divalent cations (M) within the hydroxide slab. The structure is stabilized by a hydrogen-bound network between the water molecules, the anions and the slab hydroxyls as well as by the electrostatic interactions between the slab and the $\mathrm{X}^{n-}$ anions which act as pillars within the structure.

LDHs materials obtained from solution by precipitation are often poorly crystallized and exhibit composition fluctuations. This inhomogeneity results from the difference in precipitation $\mathrm{pH}$ of $\mathrm{M}(\mathrm{OH})_{2}$ and $\mathrm{L}(\mathrm{OH})_{3}$ hydroxides. It follows that the trivalent cation content $y$ in the recovered material can be different from the solution composition. In order to avoid this type of drawback, a new 'chimie douce' process for the preparation of LDHs has been used in our Institute. The synthesis is carried out in two steps: building of the hydroxide slab and the intercalation of the anionic species $\left(\mathrm{X}^{n-}\right)$ into the interslab space are decoupled. With such a method the anionic amount is indeed directly related to its negative charge $(n)$ and to the concentration of $\mathrm{L}$ cations $(y)$ within the slab, which is chosen and fixed during the step of the slab building. Thus for illustrating this method, we have chosen to intercalate two different anionic species: (i) metavanadate chains into a nickelcobalt LDHs, and (ii) acrylic monomers and polymers into nickel-iron LDHs. In both the cases the corresponding oxy-hydroxides used as host structure were prepared by an oxidizing hydrolysis of layered oxides as $\mathrm{NaNi}_{-y}^{\mathrm{III}} \mathrm{Cd}_{y}^{\text {III }} \mathrm{O}_{2}$ and $\mathrm{NaNi}_{1-y}^{\mathrm{III}} \mathrm{Fe}_{y}^{\mathrm{III}} \mathrm{O}_{2}$ synthesized by 'ceramic method', in other words by using the high temperature chemistry (figure 7a). The intercalation of the anionic species is in a reducing medium containing $\mathrm{H}_{2} \mathrm{O}_{2}$, at $\mathrm{pH} \simeq 4$, and the anionic species to be intercalated (vanadate ions or organic (polyanions)) (figure 7b). In the case of the intercalation of the vanadate ions, the results show that disperoxovanadate ions are first intercalated, which then polycondense to give rise to $\left(\mathrm{VO}_{3}\right)_{n}^{n-}$ metavanadate chains that are finally partially grafted onto the brucite-type slabs (Han et al 1997; Ménétrier et al 1997). For acrylate-intercalated materials, the use of free-radical initiator led to polymerization of intercalated monomers (Rey et al 1998).

\section{Nonconventional synthesis method for preparing solids}

Although solid state chemists have numerous methods of synthesis at their disposal, nevertheless one of their missions is to explore permanently new techniques of synthesis involving simultaneously several parameters chosen, for example, among pressure, temperature, magnetic field, electric field, electrochemical potentials, etc... in order to create new driving forces for carrying out the chemical reactions. We have chosen for this article the presentation of two techniques, to illustrate the efforts made in our Institute, in the search for new synthesis methods: (i) the supercritical fluid processing and (ii) the mechanical alloying.

\subsection{Supercritical fluid processing}

Supercritical fluid processes are being used in many areas such as supercritical fluid separation (petroleumchemistry separation and purification, food chemistry) and supercritical fluid chromatography (analytical and preparative separation, determination of physicochemical properties). Supercritical fluids (SCFs) are also used as reactive media in various fields as environment (waste destruction, polymer recycling), geology and mineralogy (volcanoes, geothermal energy, hydrothermal synthesis), preparation of nano-sized particles, fibres and substrates (pharmaceuticals, explosives, coatings), drying materials (gels) etc... The readers can obtain detailed information on these from reviews by Matson and Smith (1989),
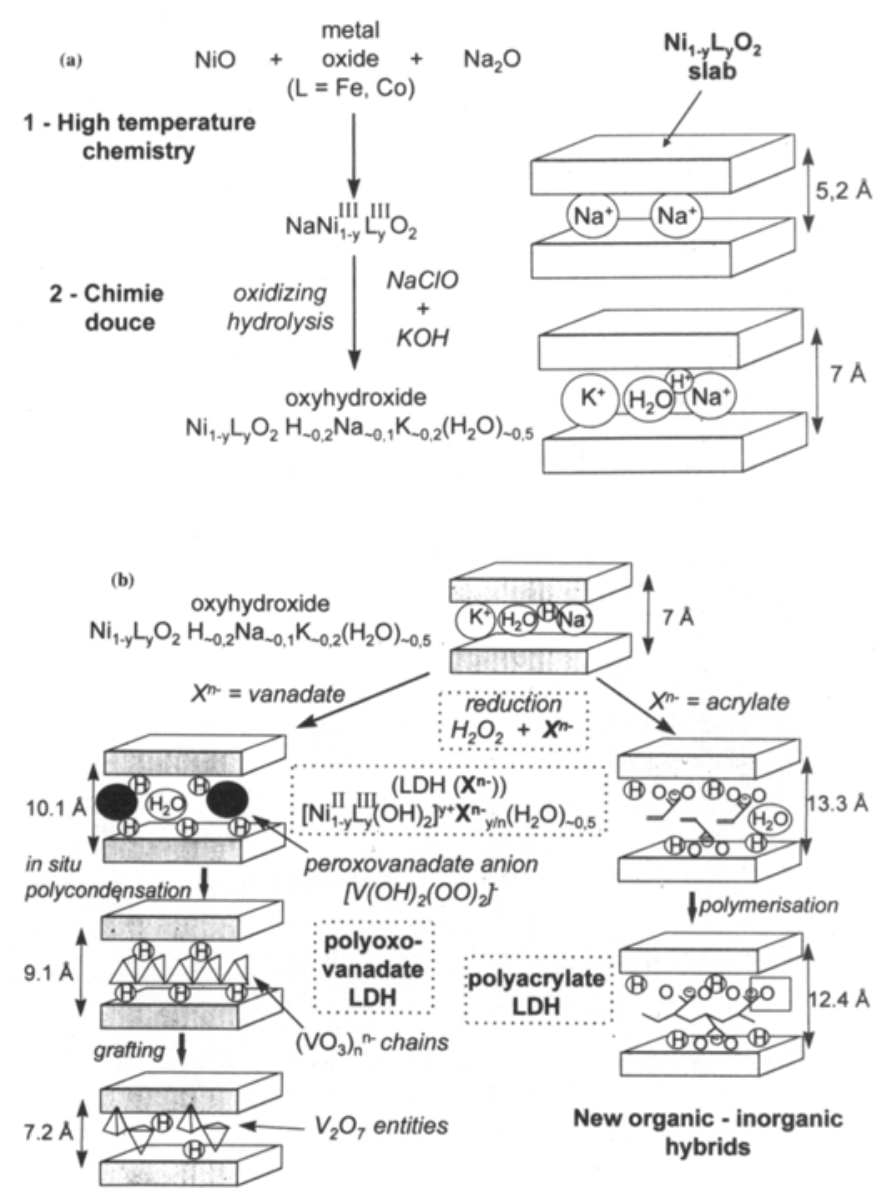

Figure 7. (a) Preparation flow chart of the LDHs by oxidizing hydrolysis of the layered oxide, before intercalation of peroxovanadates or acrylate anions and (b) preparation flow chart of the LDHs containing polycondensed metavanadate chains and acrylic monomers and polymers. 
Garrabos et al (1992), Subra (1995), Xi-Yin Zheng et al (1996), Eckert et al (1996) and Cansell et al (1998a,b).

Supercritical fluid (SCF) exhibit properties which are intermediate between gas and liquid-like, and it can never be liquified by compression; its density is 100 to 1000 times greater than those of the corresponding gases, and its compressibility is very high near the critical point. Knowing that the solvent power of a fluid i.e. the solubility of solutes, varies as a power law with respect to density, that of SCF is orders of magnitude larger than the ideal gases $\left(10^{4}-10^{8}\right)$ and smaller than that of the corresponding liquid, but nevertheless it is appreciable. Furthermore, the diffusivity of solutes in SCF is clearly higher than in liquids and the viscosity of solutes is lower than in liquid. Accordingly both diffusivity and viscosity facilitate the mass-transfer in SCF media.

Due to their particular physico-chemical properties, SCF exhibit 'exotic' media for materials processing and the viscosity, diffusivity, dielectric constant, ion product, chemical equilibrium and reaction rate constants are relatively easy to be tuned by variation of pressure and temperature in the vicinity of the critical point. Accordingly, while on the one hand large solubility variations allows selective dissolution or precipitation of solutes, on the other hand chemical reactions in SCF can be easier than in liquids due to vigorous movement of chemical species, clearly involving a higher mass-transfer.

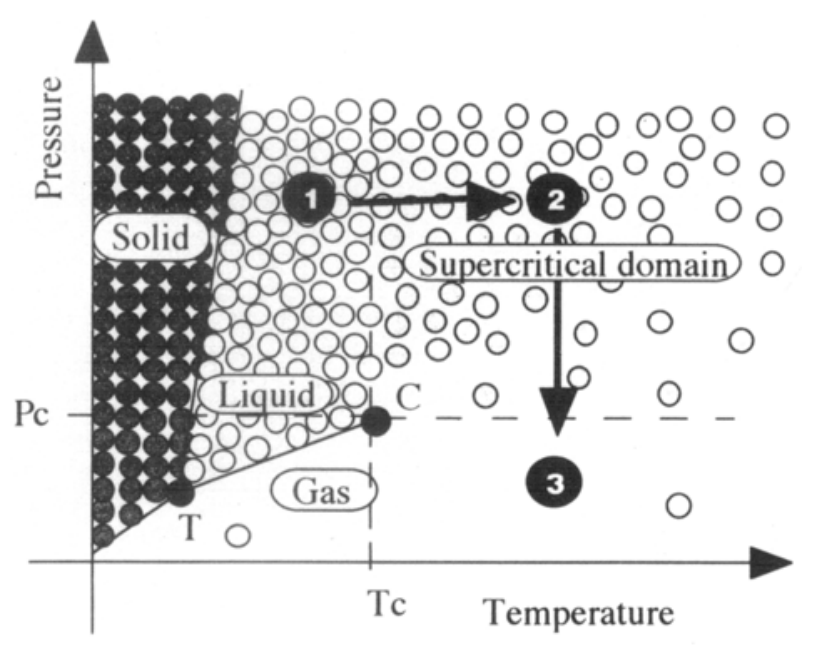

step one : solubilization of solutes in dense fluid ; step two: chemical or physical transformation ;

step three: materials recovery in low density fluid.

Figure 8. Schematic representation of a phase diagramme. illustrating density variation from liquid to gas without crossing $\mathrm{T}-\mathrm{C}$ line, $\mathrm{C}$ being the critical point and $\mathrm{T}$ the triple point.
Chemical reactions in supercritical fluid media have been schematically represented in figures 8 and 9 . Three cases can be distinguished after ascertaining whether solutes or precursors react directly or not with the SCF. Case 1: a direct reaction takes place between the solute or the precursor with the SCF (solvolysis in cell B, step 2); Case 2: the solute or the precursor is solubilized in dense fluid (cell $\mathrm{A}$, step 1), then decomposes (thermolysis) and reacts with the SCF in cell B (solvolysis, step 2); Case 3: the solute or the precursor is solubilized in dense fluid (cell A, step 1) and then decomposes in the SCF (thermolysis in cell B, step 2).

The three cases mentioned above are illustrated by significant examples studied recently in our Institute.

3.1a Preparation of new materials involving a direct reaction between the precursor and the SCF (case 1): Preparation of new oxy-(hydroxy)-fluorides exhibiting an open structure of hollandite-type (Cansell et al 1998b): A new hydroxy-fluoride $\mathrm{Fe}^{3+} \mathrm{OF}_{1-\varepsilon}(\mathrm{OH})_{\varepsilon}, n \mathrm{H}_{2} \mathrm{O}(\varepsilon \leq 0 \cdot 1$ and $0 \leq n<0.25$ ) containing a small amount of hydroxyl anions has been prepared with a high degree of crystallization by reaction of the precursor $\mathrm{NH}_{4} \mathrm{Fe}^{2+} \mathrm{F}_{3}$ with a $\mathrm{SCF}\left(T=150^{\circ} \mathrm{C}, P=30 \mathrm{Mpa}, t=30 \mathrm{mn}\right)$ consisting of: (i) $s \mathrm{CO}_{2}$ (supercritical state) for decreasing the critical parameters $\left(P_{\mathrm{c}}\right.$ and $T_{\mathrm{c}}$ ) of the reactive medium, (ii) $\mathrm{H}_{2} \mathrm{O}_{2} / \mathrm{H}_{2} \mathrm{O}$ for oxidizing $\mathrm{Fe}^{2+}$ into $\mathrm{Fe}^{3+}$, and (iii) $\mathrm{CH}_{3} \mathrm{CH}_{2} \mathrm{OH}$ for removing water.

Further experiments are in progress for obtaining a pure $\mathrm{FeOF}$ phase with the hollandite-type structure, which so far could not be prepared by any other means other than $\mathrm{SCF}$ as chemical reactive media. FeOF synthesized by conventional solid state chemistry routes exhibits the rutile-type structure.

Preparation of a new lamellar oxide deriving from a natural phyllosilicate as $\mathrm{KMg}_{3} \mathrm{AlSi}_{3} \mathrm{O}_{10}(\mathrm{OH})_{2}$ (mica) (Reig et al 1995): Knowing the existence of the fluorphlogopite $\mathrm{KMg}_{3}\left(\mathrm{AlSi}_{3}\right) \mathrm{O}_{10} \mathrm{~F}_{2}$ mica (Cooper and Hall

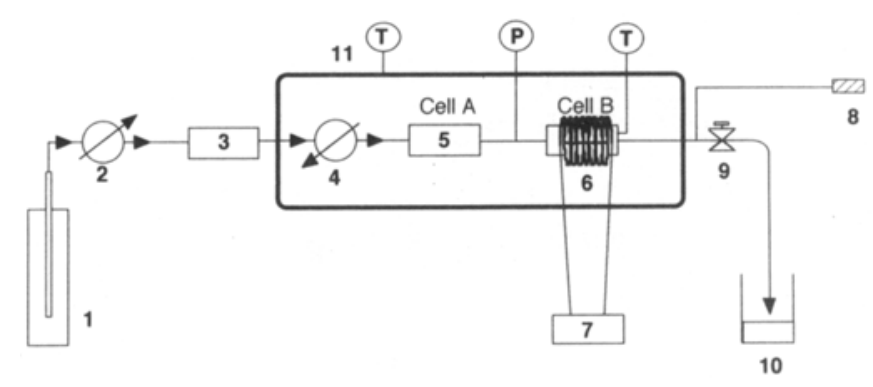

Figure 9. Apparatus for chemical synthesis in supercritical fluid media. (1. Fluid tank, 2. cooling system, 3. high pressure pump, 4. heat exchanger, 5. mass exchanger (cell A), 6. reactor (cell B), 7. temperature regulator, 8. contact breaker, 9. micrometric valve, 10 . solvent trap and 11 . oven). 
1993), all attempts for obtaining the isostructural oxygenated phase as $\mathrm{KMg}_{2} \mathrm{AlSi}_{4} \mathrm{O}_{12}$ have failed by using the methods of classical solid state chemistry. However, we have succeeded in the preparation of the pure lamellar oxygenated phase by treating a gel under supercritical conditions with 2-methoxyethanol $\left(T=600-800^{\circ} \mathrm{C}\right.$, $P=50-100 \mathrm{Mpa}, \quad t=24-72 \mathrm{~h})$. The gel was formed from alkoxides $\left[\mathrm{Si}\left(\mathrm{OC}_{2} \mathrm{H}_{5}\right)_{4}, \mathrm{Al}\left(\mathrm{OC}_{6} \mathrm{H}_{4}\right)_{3}, \mathrm{Mg}\left(\mathrm{OC}_{2} \mathrm{H}_{5}\right)_{2}\right.$, and $\mathrm{KOCH}_{3}$ ] dissolved in monomethyl ether or 2methoxyethanol.

Preparation of a new carbon-nitride $C_{3} N_{4}$ exhibiting a layered structure (Montigaud et al 1998; Alvès et al 1998): One of the challenges for obtaining ultra-hard materials is the preparation of $\mathrm{C}_{3} \mathrm{~N}_{4}$ with a $3 \mathrm{D}$ structure isostructural with that of $\beta-\mathrm{Si}_{3} \mathrm{~N}_{4}$. According to the calculations, the bulk modulus of the $3 \mathrm{D}-\mathrm{C}_{3} \mathrm{~N}_{4}$ hypothetic phase could be similar to that observed for diamond $\left(B_{\text {obs }}=442 \mathrm{Gpa}\right)$.

Using the same strategy that has been developed for both the diamond and c-BN, our goal was, using step 1 , to prepare the graphitic form of $\mathrm{g}-\mathrm{C}_{3} \mathrm{~N}_{4}$ to use it as a precursor in a flux-assisted conversion process. Thus g- $\mathrm{C}_{3} \mathrm{~N}_{4}$ was obtained by the thermolysis of the melamine $\mathrm{C}_{3} \mathrm{~N}_{6} \mathrm{H}_{6} \quad\left(T=800-850^{\circ} \mathrm{C}, \quad P=2 \cdot 5-3 \mathrm{Gpa}\right)$ using the hydrazine as nitriding solvent. XRD (ID09 beamline at ESRF-Grenoble), HRTEM, FTIR spectroscopy, TGA and XPS characterizations seem to show that the $\mathrm{C}_{3} \mathrm{~N}_{4}$ phase is a layered compound exhibiting an orthorhombic symmetry.

3.1b Preparation of copper metal by thermolysis (case 3) and copper nitride by solvolysis (case 2) (Cansell et al 1998b): For both copper metal and copper nitride, the acetyl-acetonate $\mathrm{Cu}(\mathrm{AcAc})_{2}$ used as precursor is solubilized in step 1 in a liquid phase $\left(T=90-150^{\circ} \mathrm{C}\right.$; $P=10 \mathrm{MPa}$ ). After solubilization of the precursor in the liquid containing $\left(s \mathrm{CO}_{2}+\mathrm{CH}_{3} \mathrm{CH}_{2} \mathrm{OH}\right)$, a thermolysis is performed under superconditions $\left(T=200^{\circ} \mathrm{C} ; P=15 \mathrm{MPa}\right)$ for getting copper nanoparticles $(d \simeq 50 \mathrm{~nm})$. With liquid $\mathrm{NH}_{3}$ as solvent, the precursor decomposes and reacts with ammonia under supercritical conditions $\left(T=200^{\circ} \mathrm{C}\right.$; $P=17 \mathrm{MPa})$ leading to $\mathrm{Cu}_{3} \mathrm{~N}$ nanoparticles $(d \simeq 50 \mathrm{~nm})$.

\subsection{Mechanical alloying}

Since the beginning of the 70 s mechanical alloying or mechanical synthesis have become of interest because various solid state reactions have been developed with this process for obtaining new amorphous or nanocrystalline phases generally exhibiting nonequilibrium crystal structure and compositions (Gaffet et al 1995). This technique allows for the preparation of various types of interstitial compounds including hydrides, carbides, nitrides (Foct and Lecaer 1997) etc... on the one hand, and on the other hand oxides stable only at high pressure and/or high temperature. Furthermore, using this technique large quantities of these compounds can be prepared at low costs. The driving force, induced by the mechanical impacts, behind the chemical reactions or transformations results from mainly an increase of the surface contact between particles and the creation of structural defects which favours the diffusion and the atomic rearrangements. For instance, starting from pure elemental powders of $\mathrm{Mg}$ and $\mathrm{Co}$ we were able to synthesize recently the binary alloy $\mathrm{Mg}_{2} \mathrm{Co}$ by mechanosynthesis at room temperature. This compound which cannot be prepared by the classical solid-solid reaction routes, can be obtained either crystallized with likely a c.f.c. unit cell or amorphous, by using short $(\sim 100 \mathrm{~h})$ or long $(>100 \mathrm{~h})$ time milling treatment, respectively (Bobet et al 1998).

\section{Conclusions}

The purpose of this paper was not to review all the methods of synthesis used in Solid State Chemistry but rather to show those which have been developed recently in order to prepare either novel materials which could not be obtained by the conventional routes-including ceramic and now soft-chemistry methods-or existing materials at the nanometric scale. One of the objectives of the chemist is to search for new ways for avoiding brute-force methods in order to have a better control of the structure, stoichiometry and phase purity. For reaching this goal we have undertaken a reflection on the search for new driving forces for performing the chemical reactions and on the use of those already known for implementing new strategies.

Thus with the electrochemical oxidation, it has been shown that the intercalation and deintercalation of oxygen could be controlled carefully in perovskite-derivated oxides contrary to what was observed by using high oxygen pressure and high temperature. It has been evidenced that the supercritical fluid processing, which exhibits a very reactive chemical medium at moderate temperature and pressure, offers new prospects for preparing new stable or metastable compounds as oxides, oxyhydroxy-fluorides, carbon nitride etc. . . or nanometric materials as oxides, metals, nitrides, etc.... The use of a multistage synthesis for obtaining well-crystallized LDHs compounds, resulting from an understanding of the reaction mechanisms, has permitted a strict control of their chemical composition. It has also been shown that: (i) the mechanosynthesis is powerful and promising for preparing nanocrystalline and/or amorphous new intermetallics, and (ii) the use of chemical agents as $\mathrm{NO}_{2}$ or borohydrides, much forgotten by the chemists so far, leads to obtaining of solids by topotactic and nontopotactic reactions through chemical redox mechanisms. 


\section{Acknowledgements}

I would like to thank my co-workers and colleagues, J L Bobet, F Cansell, B Chevalier, B Darriet, C Delmas, G Demazeau, A Demourgues, L Guerlou-Demourgues, J P Doumerc, E Duguet, Y Garrabos, J C Grenier, A Jacob, V Pessey, S Petit, M Pouchard, A Tressaud, A Wattiaux and $F$ Weill who, in recent years, have contributed to new development in the synthesis of solids and with whom I have had numerous and fruitful discussions.

\section{References}

Alvès I, Demazeau G, Tanguy B and Weill F 1999 Solid State Commun. (to be published)

Amatucci G G, Tarascon J M and Klein L C 1996 J. Electrochem. Soc. 1431114

Bobet J L, Pechev S, Chevalier B and Darriet B 1998 J. Mater. Chem. (to be published)

Cansell F, Rey S and Beslin P 1998a Revue de l'Institut Français du Pétrole 5371

Cansell F et al $1998 \mathrm{~b}$ J. Mater. Chem. (to be published)

Cavani F, Trifiro F and Vaccari A 1991 Catal. Today 11173

Cooper R E and Hall P C 1993 J. Am. Ceram. Soc. 761265

Corbett J D, Cheetham A K and Day P (eds) 1987 Solid state chemistry-Techniques (Oxford: Clarendon Press) p. 1

Darriet J and Subramanian M 1995 J. Mater. Chem. 5543

Disalvo F J 1990 Science 247647

Dussarat C, Grasset F and Darriet J 1995 Eur. J. Solid State Inorg. Chem. 32557

Eckert C H, Knutson B L and Debenedetti P G 1996 Nature 383313

Etoumeau J 1991 Inorganic reactions and methods (eds) J J Zuckerman and A P Hagen (New York: V C H Publishers Inc) Vol. 13 p. 202

Foct J and Lecaer G 1997 Ann. Chim. Sc. Mat. 22387

Gaffet E, Abdellaoui M and Malhouroux-Gaffet N 1995 Mater. Trans. JIM 36198

Garrabos Y, Le Neindre B, Subra P, Cansell F and Pommier C 1992 Ann. Chim. Fr 1755

Gerand B, Novogrocki G, Guenot J and Figlarz M $1979 \mathrm{~J}$. Solid State Chem. 29429

Gopalakrishnan J 1995 Chem. Mater. 71265

Gopalakrishnan J 1996 Current opinion in solid state and materials science (UK: Current Chemistry Ltd.) 1285

Grenier J C, Wattiaux A, Lagueyte N, Park J C, Marquestaut E, Etoumeau J and Pouchard M 1991 Physica C173 139
Grenier J C et al 1998 J. Mater. Chem. (to be published)

Gupta R and Manthiram A 1996 J. Solid State Chem. 121483

Hagenmuller P (ed.) 1972 Preparative methods in solid state chemistry (New York: Academic Press)

Han K S, Guerlou-Demourgues L and Delmas C 1997 Solid State lonics 9885

Jacob A, Wattiaux A, Delville M H, Marquestaut E, Bassat J M, Grenier J C, Pouchard M and Etoumeau J 1998 (private communication)

Jones W and Chibwe M 1990 in Pillared layered structures (ed.) I V Mitchell (London: Elsevier) p. 67

Manthiram A and Tsang C 1996 J. Electrochem. Soc. 143 L143

Matson D W and Smith R D 1989 J. Am. Ceram. Soc. 72871

Ménétrier M, Han K S, Guerlou-Demourgues L and Delmas C 1997 Inorg. Chem. 362441

Montigaud H, Tanguy B, Demazeau G, Alves I, Birot M and Dunogues J 1998 Proceedings of the international symposium of nitride (Ireland: Limerick)

Petit S, Doumerc J P, Grenier J C, Séguelong T and Pouchard M 1995 CR Acad. Sci. Paris 32137

Petit S, David K, Doumerc J P, Grenier J C, Séguelong $\mathrm{T}$ and Pouchard M 1998 CR Acad. Sci. Paris 1517

Pommier C 1992 Ann. Chim. Fr. 1755

Rao C N R 1993 Mater. Sci. \& Eng. B18 1

Rao C N R and Gopalakrishnan J 1986 New directions in solid state chemistry (Cambridge: Cambridge Univ. Press)

Reig P, Demazeau G and Naslain R 1995 Euro. J. Solid State Inorg. Chem. 32439

Rey S, Merida-Robles J, Han Kyoo-Seung, Guerlou-Demourgues L, Delmas C and Duguet E 1998 Polym. Int. (to be published)

Richard C, Catlow A, Bell R G and Gale J D 1994 J. Mater. Chem. 4781

Rouxel J, Toumoux R and Brec R 1994 Soft chemistry routes to new materials - Materials science forum (USA: Trans Tech. Publications)

Schollhorn R 1996 Angew. Chem. Int. Ed. 352338 (in English)

Subra P 1995 Ann. Chim. Fr 20305

Takayama-Muromachi E, Sasaki T and Matsui Y 1993 Physica C207 97

Trari M, Töpfer J, Doumerc J P, Pouchard M, Ammar A and Hagenmuller P 1994 J. Solid State Chem. 111104

Tsang C, Dananjay A, Kim J and Manthiram A 1996 Inorg. Chem. 35304

Wattiaux A, Park J C, Grenier J C and Pouchard M $1990 C R$ Acad. Sci. 3101047

Wizanski A R, Rauch P E and Disalvo F J $1989 \mathrm{~J}$. Solid State Chem. 81203

Xi-Yin Zheng, Yasuhiko Arai and Takeshi Furuya 1996 Trends Chem. Eng. 3205

Zhang L and Manthiram A 1996 J. Mater. Chem. 6999 